\title{
Visceral leishmaniasis in the Syrian Arab Republic: early detection using rK39
}

\author{
S. Al-Nahhas, ${ }^{1}$ M. Shabaan, ${ }^{1}$ L. Hammoud,${ }^{1}$ A. Al-Taweel ${ }^{2}$ and S. Al-Jorf ${ }^{2}$
}

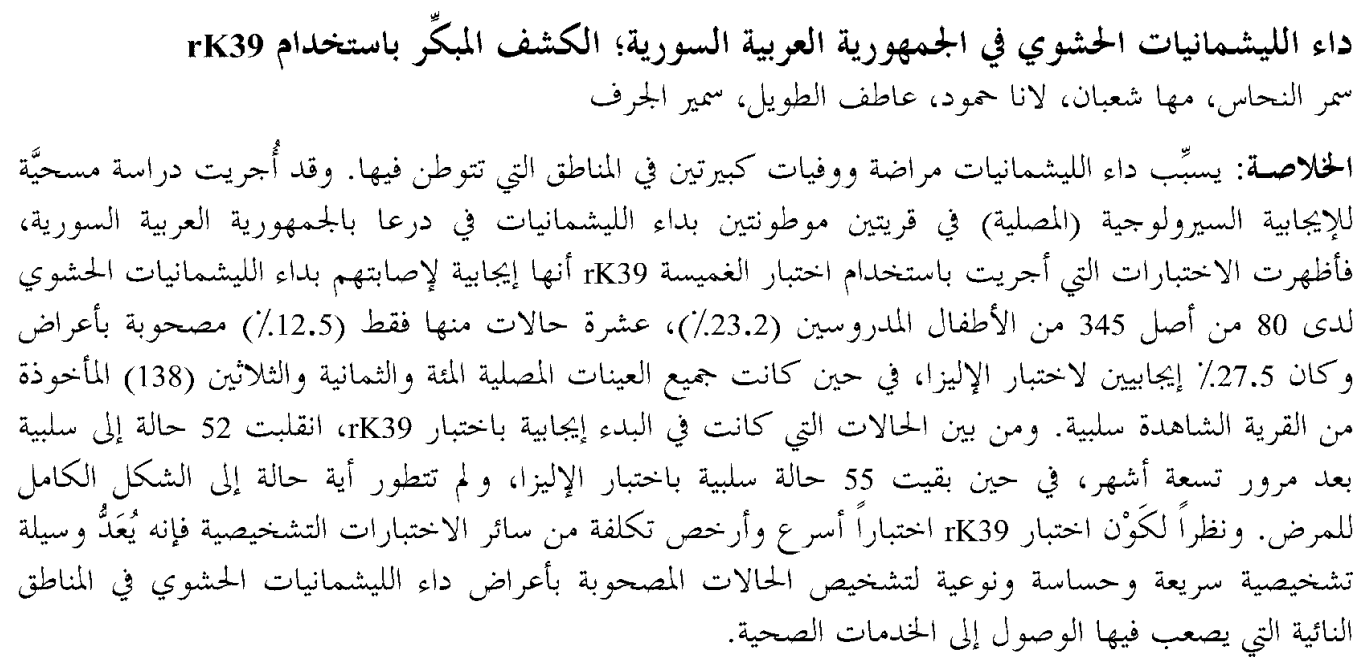

ABSTRACT Leishmaniasis causes significant morbidity and mortality in areas where it is endemic. A seroprevalence survey was conducted in 2 endemic villages in Daraa, Syrian Arab Republic, where 80 out of 345 children (23.2\%) tested positive for visceral leishmaniasis (VL) using rK39 dipstick test. Only 10 cases were symptomatic $(12.5 \%)$, and $27.5 \%$ were positive by ELISA test. All the sera $(N=138)$ obtained from the control village were negative. Of the rK39 initially positive cases, 52 had seroconverted to negative 9 months later, 55 remained ELISA negative, and none developed the full-blown disease. Being faster and less expensive than other diagnostic tests, rK39 is a rapid, sensitive and specific diagnostic tool for symptomatic cases of $\mathrm{VL}$ in remote areas with poor accessibility to health services.

La leishmaniose viscérale en République arabe syrienne : détection précoce en utilisant le rK39 RESUME La leishmaniose entraîne une morbidité et une mortalité importantes dans les zones où elle est endémique. Une enquête de séroprévalence a été réalisée dans 2 villages d'endémie à Dera (République arabe syrienne) où 80 enfants sur $345(23,2 \%)$ ont été testés positifs à la leishmaniose viscérale en utilisant le test rapide sur bandelette réactive rK39. Seulement 10 cas étaient symptomatiques (12,5\%), et 27,5\% étaient positifs au test ELISA. Tous les sérums $(n=138)$ prélevés dans le village témoin étaient négatifs. Parmi les cas initialement positifs au rK39, 52 étaient devenus séronégatifs 9 mois plus tard, 55 sont restés négatifs à l'ELISA, et aucun n'a développé la forme floride de la maladie. Plus rapide et moins coûteux que les autres tests diagnostiques, le rK39 est un outil diagnostique rapide, sensible et spécifique pour les cas symptomatiques de leishmaniose viscérale dans les zones éloignées où l'accès aux services sanitaires est difficile.

${ }^{1}$ Department of Biology, Faculty of Science, University of Damascus, Damascus, Syrian Arab Republic. ${ }^{2}$ Public Health Department, Ministry of Health, Damascus, Syrian Arab Republic. 


\section{Introduction}

Leishmania spp. are protozoa which cause cutaneous, mucocutaneous and visceral leishmaniasis in man. About 1.5 million cases of cutaneous leishmaniasis and 100 000-500 000 cases of visceral leishmaniasis (VL) occur annually. Human VL is a serious illness that can give rise to epidemics and cause high mortality [1,2].

At present, routine diagnosis of VL is done by direct microscopic examination of patient material or by culture [2-4]. The microscopic detection of amastigotes in Giemsa-stained spleen, bone marrow or lymph node aspirates is simple and cheap, but spleen aspiration can be a dangerous procedure under field conditions, and isolation of parasites by culturing is timeconsuming, expensive and difficult [3-6].

Serodiagnosis has been widely utilized because anti-leishmanial antibody titres are high, especially during the acute phase. The preferred method of diagnosis in the laboratory situation is by enzyme-linked immunosorbent assay (ELISA), fluorescent antibody or direct agglutination tests [710]. For effective screening of infected humans and reservoirs, however, there is a need to adopt a simple, sensitive and specific diagnostic test. The rapid assay for qualitative determination of antibodies to rK39, an antigen specific for VL caused by parasites of the $L$. donovani complex, is considered a reliable new test [11-18]. The use of this antigen as a rapid tool for detecting VL is not established in the Syrian Arab Republic or in neighbouring countries.

Visceral leishmaniasis is endemic throughout most of the Mediterranean basin countries, France, Italy, Lebanon, Syrian Arab Republic, Algeria, etc., since the whole area is one biogeographical entity. Data from the Division of Disease Control in the Syrian Arab Republic report 37 cases of VL for 2000 and 35 cases for 2001, distributed into two main endemic areas, near the coast (Latakia, Tartous, Aleppo and Idleb), where cases of human VL (especially in children) have been found $[19,20]$, and in the south, between Dara and Suwayda.

The main objectives of this study were to assess the efficacy of the rK39 test for early detection of VL cases in children under 5 years in endemic villages, as well as testing its prognostic value in the follow-up of the subclinical and acute cases in these villages.

\section{Methods}

\section{Study area}

Two villages, Sour and Assem, located between Dara and Suwayda in the south of the country were selected for the following reasons:

- proximity to Damascus (50-70 km), so that samples can be transported to the laboratory quickly, ensuring accuracy of results;

- local conditions, namely the volcanic rocky hills, low altitude and high humidity, an environment suitable for both reservoir and vector species;

- presence of a very high density of Phlebotomus spp. inside and outside the homes;

- incidence of cases of VL in these two villages in the previous 2 years.

Ottaya village was selected as a negative control for VL infections; the village is distant from the endemic tested areas and no cases of VL have been reported there.

\section{Screening childhood population by rK39 dipstick test}

A cross-sectional survey was conducted in the three study villages. There is no public

المجلة الصحية لشرق المتوسط، منظمة الصحة العالمية، المجلد التاسع، العدد ع، ب... 
health centre in the villages, so a household survey conducted by doctors and technicians was carried out. This was done in May, September and November 2001 and April 2002, these months being chosen as Syrian Ministry of Health reports indicate that the number of cases of VL is greater during these times. All children (483) between 6 months and 6 years residing in the 3 villages were tested for VL using rK39 dipsticks.

A drop of peripheral blood is added to the rK39 dipstick (InBios International, United States of America), after which the chase buffer solution, which allows blood proteins to migrate upward, is added. The results can be read in 5-10 minutes. The test is positive when double bands (control line and test line) appear in the test strip, while the presence of a single control line indicates a negative result $[15,16]$.

The follow-up of the cases testing positive by rK39 was carried out in December 2002, both clinically and serologically.

\section{Parasitological examination}

Bone marrow aspirates were obtained from 10 of the children testing positive for $\mathrm{VL}$ (parental consent was refused in the remaining cases). The procedure was done in hospitals in Damascus since there were no local health care facilities with the necessary equipment. Smears prepared from the aspirates were stained with Giemsa stain and diagnosis of VL was confirmed by the microscopic detection of amastigotes.

\section{Sera sample collection}

For each child, a data collection form was completed which included information about the child and whether any signs and symptoms of the disease were present. Sera samples were obtained only from positive children (80 sera) and stored at $-20^{\circ} \mathrm{C}$ until use.

\section{ELISA test}

In order to identify the sera antibody titres, serum samples were tested by ELISA (Bordier Affinity Products, Switzerland) [21,22]. Breakable ELISA strips were sensitized with $L$. infantum soluble antigens. The wells were blocked with TBS-Tw. After removing the blocking solution, the wells were incubated with diluted serum samples, then washed 4 times with washing solution and incubated with conjugate. The conjugate was then removed and the wells were washed and incubated with the substrate. Finally the strips were read at $405 \mathrm{~nm}$ in the PersonalLAB ${ }^{\mathrm{TM}}$ (Biochem ImmunoSystems, Italy) ELISA reader.

\section{Results}

Table 1 shows the results of the screening of the childhood populations in the two endemic villages. Eighty out of 345 samples were rK39 positive, recording a seroprevalence of $23.2 \%$, which was statistically higher in Assem compared to Sour village. There was no significant difference between males and females regarding the prevalence of infection. All the sera (N138) obtained from the control village, Ottaya, were negative (single band).

Table 1 Screening childhood populations for visceral leishmaniasis in the two endemic villages using rK39

\begin{tabular}{lccc}
\hline Village & $\begin{array}{c}\text { No. of children } \\
\text { screened }\end{array}$ & $\begin{array}{c}\text { No. positive, } \\
\text { rK39 }\end{array}$ & $\%$ \\
\hline Sour & 204 & 35 & 17.2 \\
Assem & 141 & 45 & 31.9 \\
Total & 345 & 80 & 23.2 \\
\hline $\begin{array}{l}\text { All 138 subjects in the control village, Ottaya, } \\
\text { tested negative by rK39 dipstick test. }\end{array}$
\end{tabular}


Sera from patients with acute VL were easily identified by rK39 test, but patients with asymptomatic or self-healing infections had low or undetectable levels of antirK39 antibodies.

Microscopic examination for amastigotes in bone marrow aspirates was only performed in 10 out of the 80 positive cases due to the high parental refusal rate. All 10 cases tested proved to be positive for VL (sensitivity 100\%). Most of children who were positive by rK39 dipstick were asymptomatic (Figure 1a) and the number of leishmania amastigotes identified inside and outside macrophages in the stained bone marrow aspirates was lower in this asymptomatic group compared with the symptomatic children (Figure 1b). Symptoms included irregular fever (for one day), cough, diarrhoea, loss of weight and hepato-splenomegaly $(2-3 \mathrm{~cm})$.

The sera of the 80 positive cases by rK39 dipstick test were tested by ELISA, but only $27.5 \%$ were proved positive (Table 2).

Nine months after the first visit, 55 out of the 80 children (68.8\%) who tested positive by rK39 dipstick were followed up clinically and serologically. All these children appeared healthy with no evidence of

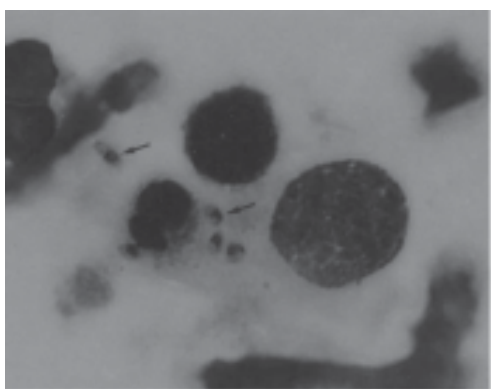

a full-blown disease except for 4 children with enlarged lymph glands. Serologically, the data obtained after applying the rK39 dipstick test presented only 3 weakly positive children (similar to their previous results) with the rest of the samples (52 sera) testing negative.

ELISA test results were negative in all 55 cases tested at the 9-month follow-up, i.e. no variation from earlier results. This indicates that ELISA is more sensitive in diagnosis of the disease since it recorded a lower frequency of false positive cases compared to rK39.

\section{Discussion}

This study showed that rK39 is a reliable serologic indicator of VL infection. The specificity of this recombinant product, which is part of a large kinesin-related protein expressed by amastigotes [11,23], has been previously reported using sera from patients with other tropical diseases $[13,14,24,25]$.

According to many studies, the fact that rK39 predominantly exists in amastigotes (the pathologic form) and not in promastigotes, could explain the high titres of anti-

\section{b) symptomatic children}

Figure1 Amastigotes inside and outside the macrophage in: a) asymptomatic children;

المجلة الصحية لشرق المتوسط، منظمة الصحة العالمية، المجلد التاسع، العدد ؟، ب... 
Table 2 Comparison of rK39 dipstick test and ELISA test

\begin{tabular}{lcrrc}
\hline Village & + rK39 & \multicolumn{1}{c}{$\%$} & +ELISA & $\%$ \\
\hline Sour & 35 & 43.8 & 8 & 10.0 \\
Assem & 45 & 56.3 & 14 & 17.5 \\
Total & 80 & 100.0 & 22 & 27.5
\end{tabular}

All 138 subjects in the control village, Ottaya, tested negative by rK39 dipstick test.

rK39 antibodies in patients with acute VL and relatively lower titres in those infected but asymptomatic [13,14,26,27].

There was poor agreement between rK39 and ELISA results. The number of sera testing positive by ELISA was 22 (27.5\%) of the 80 which tested positive using rK39 dipstick. However, it is worth mentioning that this is consistent with other studies that reported that ELISA test using rK39 was more sensitive and specific than the ELISA test using soluble antigen [1114].

Only 10 of the 80 children testing positive were symptomatic (12.5\%), and in 3 of these 10 cases microscopic examination for amastigotes was positive. Most children who tested positive by rK39 dipstick were asymptomatic, and few Leishmania amastigotes were identified inside and outside macrophages in comparison with the symptomatic children. The difficulty in the demonstration of parasites in asymptomatic or sub-clinical patients has been reported in other studies [13-15,27].
These results indicate that the use of rK39 strips is a relatively sensitive test method because it can detect even a very small quantity of antibodies resulting from individual specific immunological response to insect bites. These results, however, also indicate that rK39 is unable to differentiate between recent and old infection, and that the existence of clinical signs and symptoms is necessary to diagnose VL in cases with positive test results.

In conclusion, rK39 could be used as a rapid, sensitive and specific diagnostic test for visceral leishmaniasis in symptomatic cases living in remote areas where there is poor accessibility to health services. The test is quick (results are obtained in 5-10 minutes) and no special equipment is needed. In disease endemic countries, VL can easily be misdiagnosed on a clinical basis, therefore, screening populations using rK39 test is recommended for early diagnosis and treatment of the disease, thereby reducing its morbidity and mortality.

\section{Acknowledgement}

This investigation received technical and financial support from the joint WHO Eastern Mediterranean Region (EMR), Division of Communicable Diseases (DCD) and the WHO Special Programme for Research and Training in Tropical Diseases (TDR): the EMRO/DCD/TDR Small Grants Scheme for Operational Research in Tropical and Communicable Diseases.

\section{References}

1. Brecelj M, Pikelj F, Anderluh G. Polymerase chain reaction as a diagnostic tool for detecting Leishmania. Infection, 2000, 28 (2):111-3.

2. Osman OF, et al. Evaluation of PCR for diagnosis of visceral leishmaniasis.
Journal of clinical microbiology, 1997, 35(10):2454-7.

3. De-Brujin MHL et al. A comparative study of diagnosis by the polymerase chain reaction and by current clinical methods using biopsies from Colombian 
patients with suspected leishmaniasis. Tropical medicine and parasitology, 1993, 44:201-7.

4. Control of the leishmaniases: report of a WHO expert committee. Geneva, World Health Organization, 1990 (WHO Technical Report Series 793).

5. Chulay JD, Bryceson AD. Quantitation of amastigotes of Leishmania donovani in smears of splenic aspirates from patients with visceral leishmaniasis. American journal of tropical medicine and hygiene, 1983, 32:475-9.

6. Weigle KA et al. Diagnosis of cutaneous and mucocutaneous Leishmaniasis in Colombia: a comparison of seven methods. American journal of tropical medicine and hygiene, 1987, 36:489-96.

7. Harith $A E$ et al. Evaluation of a newly developed direct agglutination test (DAT) of serodiagnosis and sero-epidemiological studies of visceral leishmaniasis: comparison with IFAT and ELISA. Transactions of the Royal Society of Tropical Medicine and Hygiene, 1987, 81:603-6.

8. Ashford DA et al. Studies on the control of visceral leishmaniasis: validation of the Falcon assay screening test-enzyme-linked immunosorbent assay for field diagnosis of canine visceral leishmaniasis. American journal of tropical medicine and hygiene, 1993, 48(1):1-8.

9. Singla $\mathrm{N}$ et al. Evaluation of the direct agglutination test as an immunodiagnostic tool for kala-azar in India. Transactions of the Royal Society of Tropical Medicine and Hygiene, 1993, 87:276-8.

10. Gupta $S$ et al. Evaluation of enzymelinked immunosorbent assay in the diagnosis of kala-azar in Malda district (West-Bengal). Indian journal of medical research, 1993, 97:242-6.

11. Burns JM Jr et al. Molecular characterization of a kinesin-related antigen of
Leishmania chagasi that detects specific antibody in African and American visceral leishmaniasis. Proceedings of the National Academy of Sciences of the United States of America, 1993, 90:7759.

12. Qu JQ et al. Serodiagnosis of Asian leishmaniasis with recombinant antigen from repetitive domain of a Leishmania kinesin. Transactions of the Royal Society of Tropical Medicine and Hygiene, 1994, 88:543-5.

13. Singh $S$ et al. Diagnostic and prognostic value of K39 recombinant antigen in Indian leishmaniasis. Journal of parasitology, 1995, 81(6):1000-3.

14. Badaro R et al. rK39: a cloned antigen of Leishmania chagasi that predicts active visceral leishmaniasis. Journal of infectious diseases, 1996, 173(3):758-61.

15. Zijlstra EE et al. Diagnosing visceral leishmaniasis with the recombinant K39strip test: experience from the Sudan. Tropical medicine and international health, 2001, 6(2):108-13.

16. Delgado $O$ et al. Value of a dipstick based on recombinant RK39 antigen for differential diagnosis of American visceral leishmaniasis from other sympatric endemic diseases in Venezuela. Parasite, 2001, 8 (4):355-7.

17. Badaro R, Reed SC, Carvalho EM. Immunofluorescent antibody test in American visceral leishmaniasis: sensitivity and specificity of different morphological forms of two Leishmania species. American journal of tropical medicine and hygiene, 1983, 32(3):480-4.

18. Pampiglione $S$ et al. Studies on Mediterranean Leishmaniasis. 2. Asymptomatic cases of visceral leishmaniasis. Transactions of the Royal Society of Tropical Medicine and Hygiene, 1974, 52:44753.

لمجلة الصحية لشرق المتوسط، منظمة الصحة العالمية، المجلد التاسع، العلد ع، بr. 
19. Lepine P. Trois cas syriens de Kala Azar infantile [Three Syrian cases of infantile kala-azar]. Bulletin de la société de pathologie exotique, 1926, 19:429-31.

20. Berberian DA. Problèmes épidémiogiques relatifs à la transmission du Bouton d'Orient et du Kala-Azar infantile au Liban [Epidemiological problems related to the transmission of cutaneous leishmaniasis and infantile kala-azar in Lebanon]. Proceedings of the sixteenth congress of tropical medicine and malaria, Lisbon, 1958.

21. Badaro $R$ et al. Evaluation of the micro enzyme-linked immunosorbent assay (ELISA) for antibodies in American visceral leishmaniasis: antigen selection for detection of infection-specific responses. American journal of tropical medicine and hygiene, 1986, 35(1):728.

22. Nassar $\mathrm{N}$ et al. Leishmaniose viscérale au cours du sida: difficultés du diagnostic sérologique, évaluation d'une nouvelle trousse ELISA [Visceral leishmaniasis in the course of AIDS: problems in serological diagnosis, evalua- tion of a new ELISA kit]. Feuillets de biologie, 1996, 37:39-42.

23. Reed SG et al. An improved serodiagnostic procedure for visceral leishmaniasis. American journal of tropical medicine and hygiene, 1990, 43:632-9.

24. Sundar S et al. Rapid accurate field diagnosis of Indian visceral leishmaniasis. Lancet, 1998, 351:563-5.

25. Jelinek T, Eichenlaub S, Loscher T. Sensitivity and specificity of a rapid immunochromatographic test for diagnosis of visceral leishmaniasis. European journal of clinical microbiology and infectious disease, 1999, 18:669-70.

26. Bern $\mathrm{C}$ et al. Use of the recombinant K39 dipstick test and the direct agglutination test in a setting endemic for visceral leishmaniasis in Nepal. American journal of tropical medicine and hygiene, 2000, 63(3-4):153-7.

27. Ozensoy $S$ et al. Serodiagnosis and epidemiology of visceral leishmaniasis in Turkey. American journal of tropical medicine and hygiene, 1998, 59(3): 363-9. 